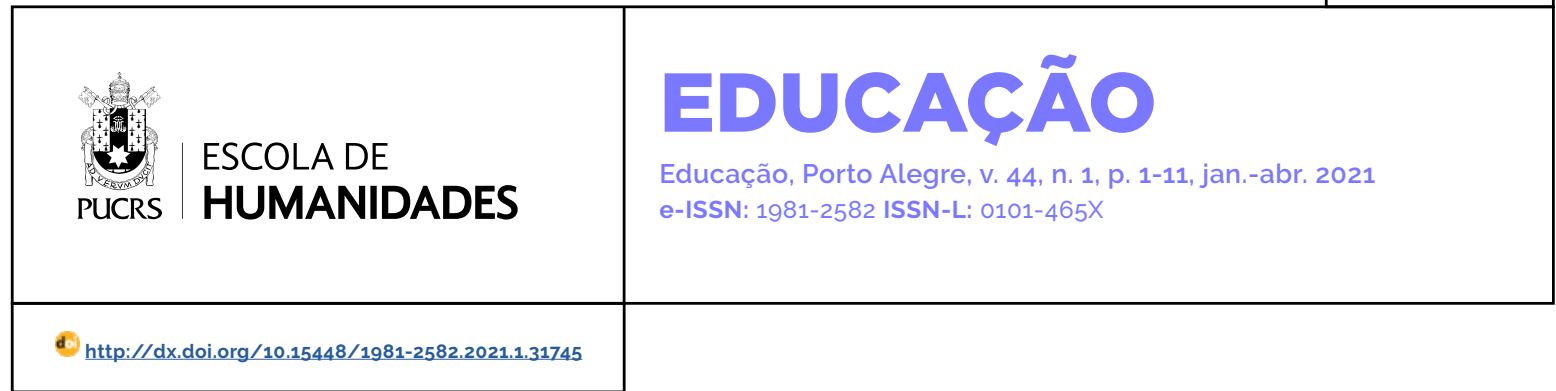

\title{
Abordagem disposicional como ferramenta para compreender o subcampo da Educação
}

\author{
Dispositional approach as a tool to understand the sub-field of Education \\ Abordaje disposicional como herramienta para comprender el subcampo de la Educación
}

\section{Célia Elizabete Caregnato $^{1}$ orcid.org/0000-0002-9326-590X celia.caregnato@gmail.com}

\section{Bernardo Sfredo}

Miorando²

orcid.org/0000-0002-7556-1684 bernardo.sfredo@gmail.com

\section{Ricardo Cortez Lopes ${ }^{3}$} orcid.org/0000-0003-0808-7203 rshicardo@hotmail.com

\section{Vinicius Foletto \\ Bevilaqua $^{1}$}

orcid.org/0000-0001-8014-187

vbevilaqua@gmail.com

Recebido em: 23 ago. 2018. Aprovado em: 22 abr. 2021. Publicado em: 21 jun. 2021

\section{(c) (i)}

Artigo está licenciado sob forma de uma licença Creative Commons Atribuição 4.0 Internacional.
Resumo: Este artigo propõe compreender aspectos da pesquisa em Educação no Brasil a partir do conceito de disposições, verificando-as em depoimentos de líderes de grupos de pesquisa. A abordagem se dá a partir da sociologia critica, com base no arcabouço teórico desenvolvido por Pierre Bourdieu e Bernard Lahire. O material empírico é composto por entrevistas, cujo conteúdo foi categorizado através de análise qualitativa. Há evidências de disposições alinhadas àquilo que a literatura sociológica identifica como propriedades gerais do campo científico, como a competência para operar o ludus e a apetência e a competência para a interlocução. Ao mesmo tempo, emerge um conjunto de elementos que indicam disposições particulares ao subcampo da Educação, aqui caracterizadas como apetência para a intervenção socioeducacional. Tal característica, associada a ideias de emancipação e mudança social, pode ser reconhecida como uma das particularidades que compõe a singularidade da pesquisa educacional dentro do campo científico. Palavras-chave: disposições, pesquisa em educação, habitus, campo científico

Abstract: This article proposes to understand aspects of educational research in Brazil using the concept of dispositions, verifying them in statements by researchers leading research groups. The approach is based on critical sociology, from the theoretical framework developed by Pierre Bourdieu and Bernard Lahire. The empirical material comprises interviews, whose content was categorized through qualitative analysis. There is evidence of dispositions in line with what is identified in sociological literature as general properties of the scientific field, such as the competence to operate the ludus and the apetence and competence for dialogue. At the same time, there is an emerging set of elements that point out to dispositions which are particular of the Education sub-field, which we name apetence for socio-educational intervention. This feature, associated with ideas of emancipation and social change, can be recognized as one of the peculiarities that make up the singularity of educational research within the scientific field.

Keywords: dispositions, educational research, habitus, scientific field

Resumen: Este artículo propone comprender aspectos de la investigación en Educación en Brasil a partir del concepto de disposiciones, verificándolas en declaraciones de investigadores líderes de grupos de investigación. El enfoque se basa en la sociología crítica y en el marco teórico desarrollado por Pierre Bourdieu y Bernard Lahire. El material empírico consta de entrevistas, cuyo contenido ha sido categorizado mediante análisis cualitativo. Hay evidencias de disposiciones acordes con lo identificado en la literatura sociológica como propiedades generales del campo científico, como la competencia para operar el ludus y el apetito y competencia por la interlocución. Al mismo tiempo, emerge un conjunto de elementos que señalan disposiciones particulares en el subcampo Educación, al que llamamos el apetito por la intervención socioeducativa. Esta característica, asociada a los ideales de emancipación y cambio social, puede ser reconocida como una de las peculiaridades que configuran la singularidad de la investigación educativa dentro del campo científico. Palabras clave: disposiciones, investigación educativa, habitus, campo científico

\footnotetext{
Universidade Federal do Rio Grande do Sul (UFRGS), Porto Alegre, RS, Brasil.

Universidade Federal de Ciências da Saúde de Porto Alegre (UFCSPA), Porto Alegre, RS, Brasil.

Faculdade CMB, Porto Alegre, RS, Brasil.
} 
O subcampo científico da Educação apresenta uma série de documentos normativos que indicam tendências de valor ao estabelecer critérios de avaliação. Essas tendências não definem totalmente a atuação dos agentes, mas apresentam-se como um horizonte prático e moral, ou seja, como referencial para a organização de suas ações. É possivel ter uma ideia das regras do campo científico a partir desses documentos, visto que são editais ou orientações e possuem valor legal. Na medida em que essas regras vão sendo incorporadas em um patrimônio de esquemas de ação, que caracteriza um programa de socialização dos indivíduos no campo, podemos falar em disposições. Mesmo que essas regras passem por mudanças na trajetória histórica do subcampo, elas contribuem para acionar ou suspender estratégias que orientam os modos de crer e agir, fazendo com que as disposições se manifestem de formas variáveis, conforme o contexto.

Entre as normativas que organizam o subcampo da pesquisa em Educação como componente do campo científico, destacamos: (a) o Relatório de Avaliação produzido pela Comissão de Área de Educação da Coordenação de Aperfeiçoamento de Pessoal de Nivel Superior (Capes) (Capes, 2017); e (b) Critérios de Julgamento dos Comitês de Assessoramento do Conselho Nacional de Desenvolvimento Científico e Tecnológico (CNPq), especialmente da área de Educação para 2015-2017 (CNPq, 2015).

As publicações, especialmente em periódicos, são o principal produto que exprime o capital científico. Isso porque a parte dominante do subcampo também se define como portadora do habitus para o conhecimento científico. A principal tendência é a da metrificação da produção através de indicadores. São eles que permitem a construção de um programa de pós-graduação, lócus principal da produção do conhecimento científico em Educação e instituição por meio da qual se socializam os pesquisadores, reproduzindo a academia e formando novos atores. São também as métricas de produção que sustentam o julgamento dos bolsistas de produtividade, que servem como referências sobre o que é ser pesquisador no subcampo.
Outro importante parâmetro para a constituição dessa concepção são os grupos de pesquisa, que vêm obtendo reconhecimento crescente como espaço de formação de pesquisadores, especialmente em nível de pós-graduação. Entendemos que suas lideranças desempenham papel significativo na orientação da reprodução da academia brasileira. Compreender elementos que embasam sua atuação pode levar a constatar modos de crer, fazer e julgar que estruturam o habitus do subcampo e socializam os novos pesquisadores. Esses pressupostos se articulam para produzir o seguinte problema de pesquisa: que tendências disposicionais se revelam a partir de depoimentos dos pesquisadores no campo da Educação?

Para entender como esses individuos veem esses principios se materializarem em suas ações e crenças, propomos a interpretação de elementos de suas trajetórias expostos em entrevistas sob a óptica das disposições que marcam as práticas no subcampo. O nosso universo de pesquisa são os pesquisadores bolsistas de produtividade em Educação no Brasil. Nossa análise, a partir da sociologia crítica, incidiu sobre entrevistas realizadas junto a pesquisadores da nossa amostra. Assim, apresentamos, sucessivamente, a nossa base teórica, a nossa metodologia, os resultados de nossa pesquisa, a sua discussão e as conclusões.

\section{Disposições como recurso interpretativo da sociologia crítica}

Para Bourdieu (2012), os processos de diferenciação modernos geraram espaços sociais no qual atividades se desenvolvem de maneira relativamente autônoma e que se convertem em capital dentro de um campo de força estabelecido. Campos expressam espaços sociais diferenciados de estruturação de relações de poder, com regras próprias, instituições, e disputas que não se reduzem à realização dos interesses de um ou outro ator. Cada campo é marcado por uma luta específica e por uma forma específica de capital, desigualmente distribuído.

No caso do campo científico, Bourdieu (2004) sugere que os diferentes agentes científicos disputam em torno da noção do que é fazer ciência, 
o que é ser um cientista, e quais são os produtos legítimos da atividade científica. Trata-se de uma luta constante para transformar interesses particulares em interesse geral, isto é, de todos os agentes que atuam no mesmo campo.

Os pressupostos de Bourdieu partem da ideia de que essas atividades geram processos de distinção positiva. Essa distinção aparece com o acúmulo de capital, disponivel no campo de forma limitada. A capacidade de definir esse capital, controlar sua produção e seu acesso, mantendo-o escasso, delimitam maior ou menor autonomia do campo. A autonomia do campo está ligada à possibilidade de seus atores definirem o valor de seus produtos e obterem reputação, prestígio e autoridade no interior do campo e na relação com a esfera social. Dessa maneira, "só os que participam dessa competição é que podem se apropriar simbolicamente desse produto e avaliar seu mérito" (Portocarrero, 1994, p. 211).

O campo faz exigências, e os individuos que melhor as captam e as aplicam no seu interior são os que obtêm mais capital. Essas exigências são traduzidas em habitus, definido por Bourdieu como:

(...) um sistema de disposições duráveis e transponiveis que, integrando todas as experiências passadas, funciona a cada momento como uma matriz de percepções, de apreciações e de ações - e torna possivel a realização de tarefas infinitamente diferenciadas, graças às transferências analógicas de esquemas (...). (Bourdieu, 1983, p. 65)

O habitus é a manifestação no corpo - incorporação - das estruturas objetivas, representadas pelo conceito de campo, que são incorporadas como esquemas mentais a guiar as práticas dos agentes no campo. Entretanto, o habitus possui um espaço de improviso e de exteriorização, no qual se atualizam e se suspendem disposições (Lahire, 2004). A dinâmica disposicional, que varia conforme os contextos de atuação, pode contribuir para mudanças na estruturação do campo. Uma estratégia, utilizada geralmente pelos atores com menor concentração de capital, é a de forçar, consciente ou inconscientemente, suas disposições contra o estado atual das disposições predominantes e do habitus legítimo do campo. Essa disputa objetiva para legitimar as disposições não hegemônicas e tornar os produtos associados a elas fontes do capital simbólico referencial no campo.

Como componente básico do habitus, uma disposição expressa

(...) o resultado de uma ação organizadora,
apresentando então um sentido próximo ao de
palavras tais como estrutura; designa, por outro
lado, uma maneira de ser, um estado habitual
(em particular do corpo) e, em particular, uma
predisposição, uma tendência, uma propensão
ou uma inclinação. (Bourdieu, 1983)

Lahire (2002) se debruça sobre as disposições adquiridas via experiência e trajetória dos atores:

\begin{abstract}
o campo de investigação proposto aqui levanta a questão das modalidades de desencadeamento dos esquemas de ação incorporados (produzidos no decorrer do conjunto das experiências passadas) pelos elementos ou pela configuração da situação presente, isto é, a questão das maneiras como uma parte - e somente uma parte - das experiências passadas incorporadas é mobilizada, convocada e despertada pela situação presente. (Lahire, 2002, p. 52)
\end{abstract}

As disposições são encaradas neste estudo como tendências a agir e crer, pensar e julgar, que conduzem os atores nas circunstâncias e contextos presentes da sua prática, deixando em segundo plano o fator biográfico e de trajetória destacado por Lahire. A proposta de Lahire é buscar as disposições dos indivíduos no seu processo de socialização no campo pela recorrência de modos de crer e de agir em distintas situações e contextos. Porém, aqui procuramos a recorrência desses modos de agir e de crer em diferentes indivíduos que são atores destacados na estruturação dinâmica do campo.

Sustentamos que esses pesquisadores nos permitem acessar quais são essas disposições, que os fazem atrair outros pesquisadores para, com eles, formarem grupos de pesquisa. Atribuímos a eles, pelas posições de poder que ocupam, a articulação do campo. Assim, aquelas disposições que foram construídas socialmente e que estão nas suas práticas incorporadas tornam-se elementos propulsores de dinâmicas no campo e de formação de novos pesquisadores. O sucesso desses 
pesquisadores no campo, relacionado às suas disposições, nos leva a entender o próprio campo.

Nossa revisão bibliográfica sobre pesquisa acadêmica, produção de conhecimento e caracterização dos intelectuais apontou para algumas tendências da área de estudos. Nunes (2001), ao apresentar um panorama sobre as pesquisas do saber docente, já identificava uma internacionalização da área há dezessete anos. Para Cunha e Prado (2007, p. 281), a atividade de ensino por professores-pesquisadores é "fonte de conhecimento que se traduz em saber, pois partem e retornam ao seu contexto: o próprio trabalho docente". Severino (2009), ao buscar estabelecer uma metodologia a ser seguida por professores do ensino superior, vincula a legitimidade e a relevância social da pesquisa a um compromisso ético-político. Acerca dessa ligação, Santos e Azevedo (2009, p. 548), entendem que

(...) as investigações na área da política educacional, de resto como nas demais áreas das politicas públicas, certamente acabam por evidenciar com maior nitidez o movimento que articula de modo muito próximo lutas políticas (politics) e análise dos programas de ação (policy). Tal situação pode conduzir, com muita facilidade, a que a análise se torne secundária em relação à luta política, fragilizando ambas.

Mancebo (2013) analisa a atuação do professor universitário na produção do conhecimento, procurando interpretar consequências da avaliação. Ao encontrar a adesão ao jogo como uma das respostas praticadas, propõe como alternativa a revisão das regras de competição dadas pelas práticas avaliativas. Bianchetti et al., (2015), debruçando-se sobre a área da Educação, identificam transformações nas estruturas do campo científico e nos padrões de conduta dos atores a partir de um racionalismo de mercado. Induzido pela Capes, o acirramento da competição científica acaba por diminuir a autonomia tanto do campo científico em relação à sociedade quanto do subcampo da Educação em relação ao campo cientíico.

\section{Metodologia}

A discussão que apresentamos está embasada na análise de entrevistas com pesquisadores amparados por bolsas de produtividade do CNPq no topo da categorização na área de Educação que lideravam grupos de pesquisa registrados no Diretório Geral de Grupos de Pesquisa do CNPq com, no mínimo, dez anos de existência. Entendemos que o cruzamento dessas condições nos fornece elementos, não só quanto à posição de relevo, mas também quanto à concretização do trabalho de formação de novos pesquisadores.

Em trabalhos anteriores, estudamos as carreiras desses pesquisadores a partir de seus currículos, colocando especial atenção sobre algumas categorias de itens que julgamos ser propícios para identificar capital acadêmico-científico puro e político (Caregnato et al., 2016). Também detectamos mudanças entre as diferentes coortes de bolsistas de produtividade em pesquisa, comparando currículos daqueles que se encontravam na carreira em 2011 e 2015 (Caregnato et al., 2018). Neste estudo, identificamos mudanças no perfil da produção que atribuímos, entre outros fatores, à influência da avaliação da pós-graduação desempenhada pela Comissão de Aperfeiçoamento de Pessoal de Nivel Superior (Capes) nas práticas de produção e veiculação do conhecimento no Brasil. Inferimos que as mudanças, com aumento da produção de artigos, proporcionalmente à tradição na área de publicação de livros e capitulos, poderiam estar relacionadas a outras mudanças mais significativas nas disposições que compõem o habitus dos pesquisadores no campo. Portanto, neste artigo, analisamos aquilo que constitui, a partir do universo da pesquisa, as disposições do pesquisador em Educação.

A base empírica que analisamos a seguir tem origem em seis entrevistas realizadas com pesquisadores com bolsa de produtividade em pesquisa CNPq 1A, dentre os 21 que compunham o universo delimitado, até maio de 2016. Utilizamos um roteiro semiestruturado, com questões gravadas e transcritas, a fim de registrar e de classificar seu conteúdo com o auxilio do software de análise qualitativa NVivo. A análise foi realizada a partir de grandes categorias: formação do grupo de pesquisa; processos de produção do conhecimento em grupo; abordagens teóricas 
privilegiadas; abrangência da atuação; avaliação e repercussão do conhecimento produzido.

Essas grandes categorias nos permitiram obter uma visão sobre a singularidade das trajetórias de cada indivíduo no desenvolvimento de suas atividades de pesquisa em redes e visualizar o conjunto das experiências e de registros de todos os entrevistados sobre um mesmo tema abordado em todas as entrevistas. Com isso, pudemos reunir dados sobre cada uma das categorias estabelecidas a priori. Dentro delas, encontramos disposições manifestas e compartilhadas visualizáveis na forma como os entrevistados caracterizaram os seguintes tópicos: parcerias construidas para produção do conhecimento; abrangência da participação e trocas em eventos científicos; temáticas privilegiadas pelas pesquisas; e dificuldades para a produção do conhecimento no campo. Entendemos que reconstruir essas disposições com o auxilio da sociologia, caracterizando-as, permite avançar na compreensão do subcampo da Educação por elucidar as lógicas de ação social de seus artífices.

\section{Disposições para operar o subcampo da Educação}

As disposições foram construídas por meio da leitura compreensiva das entrevistas, ${ }^{4}$ o que permite situá-las em contextos das trajetórias dos pesquisadores. Foram elencadas a partir da recorrência com que apareceram no corpus de análise. Identificamos três disposições principais e as caracterizamos a partir de um enunciado que sintetiza as predisposições e práticas apresentadas.

\section{Competência para operar o ludus}

O pesquisador, ao integrar o campo, consegue perceber como o campo opera: as lógicas e as regras de suas instituições; as posições e os movimentos de seus atores. Pesquisadores em condição de liderança são capazes de mobilizar e, por vezes, formar e reformar mecanismos que potencializem suas posições. Nessa situação, parecem ir além do illusio, ao tempo em que "jogam o jogo", também analisam relativamente as condições em que ele é jogado para negociar suas posições. Isso se explicita no caso dos pesquisadores em foco quando eles tratam da formação de seus grupos e redes de pesquisa.

Uma primeira característica da competência para operar o ludus pode ser encontrada na capacidade dos pesquisadores de perceber, de forma antecipativa, os fenômenos que estão se configurando no campo. Exemplo disso é a organização de grupos e linhas de pesquisa em um determinado momento de sua trajetória, tendência que será proposta por CNPq e Capes:

Então, aqui entra o papel estratégico que foi
oferecido pelo CNPq e pela CAPES, que pas-
saram a apoiar não apenas a pesquisadora A,
o pesquisador B, mas, sobretudo, passaram
a apoiar grupos de pesquisa. (...) passaram a
apoiar linhas de pesquisa e, na medida em que
a área foi se consubstanciando, esta dimensão
de linha de pesquisa foi se tornando cada vez
mais vincada, cada vez mais plantada" (PE2).

Em alguns casos, a presença de grupos e linhas de pesquisa é anterior à própria formalização desses dispositivos pelo Diretório de Grupos de Pesquisa do CNPq e pela avaliação da Capes. Em outros casos, a organização dessas redes foi uma resposta dos pesquisadores às oportunidades de legitimação institucional e de financiamento que essa formalização propiciou.

Quando eu fui pra lá [em 1989], eu já estava com
um curriculo porque eu já tinha vários orien-
tandos de mestrado, que tinham defendido,
e eu já cheguei e fui atuando na graduação e
na pós-graduação. E eu levei essa prática do
grupo de pesquisa. Então, no começo eu tinha
três, quatro orientandos e foi fantástico porque
a gente foi criando o que poderia chamar hoje
de uma escola de orientação (PE5).

Um segundo mecanismo explicitado nas entrevistas liga-se à viabilização material da pesquisa. Frequentemente, linhas e grupos de pesquisa são fomentados através do desenvolvimento de projetos de pesquisa aprovados em editais e financiados por agência de fomento, envolvendo bolsas e auxilios, que permitem a atração de

\footnotetext{
4 Optamos por identificar os entrevistados por meio de letras e números e por não indicar dados específicos. A coleta dos depoimentos representa um material empírico produzido no processo da pesquisa e anonimizado.
} 
outros pesquisadores: "Esse grupo de pesquisa, que agora tem vinte anos, ele sempre articula, ele tem uma pesquisa até hoje, um eixo, que é em geral um projeto de pesquisa que está financiado por alguma agência" (PE6).

O terceiro grupo de estratégias de consolidação do trabalho do grupo em produto capitalizável em termos científicos é organização de publicações conjuntas: "Então, hoje ele [grupo] tem cerca de 30 participantes com certa regularidade e, nesse movimento, foram também ganhando corpo essas iniciativas de organização de livros a partir das teses deles, das teses defendidas" (PE5).

No que se refere às práticas de publicação no subcampo da Educação, em etapa anterior de nossa pesquisa, constatamos que a produção tem se modificado no sentido de privilegiar a publicação em artigos sobre livros, que foi preponderante até o início dos anos 2000 (Caregnato et al., 2018). Assim, uma estratégia emergente passa a ser a participação em conselhos editoriais e na organização de novos periódicos.

\section{Apetência e competência para a interlocução}

Para que ocorra a materialização desse trabaIho em capital científico, é preciso uma disposição para a sociabilidade de formar redes com os seus pares, mesmo que não seja uma relação simétrica. Essa abertura é um fator que permite a criação e que aumenta a produtividade individual de todos com as parcerias.

Um primeiro elemento que está ligado à apetência e à competência para a interlocução é diz respeito à mobilidade geográfica e à assertividade para interagir em outros contextos. O pesquisador de destaque se move nacional e internacionalmente. Quanto mais internacionalizado, melhores as suas chances de obter o prestígio. A possibilidade de adentrar outros lugares demanda certa facilidade para circular por localidades, instituições e circulos sociais que podem não ser aqueles em que o indivíduo se origina. Isso, por sua vez, requer uma segurança que se funda em elementos socialmente acumulados. Por um lado, vem da autoconfiança de ser afirmativo operando em espaços simbólicos a partir de um patrimônio próprio de códigos corporais, culturais, linguísticos. Por outro lado, a competência para mobilidade geográfica envolve a capacidade de mobilizar recursos materiais para assegurar a subsistência em condição de deslocamento temporário.

A busca acaba sendo por "reconhecimento que você pode ter de pesquisadores de outros países com relação à qualidade do seu trabalho" (PE2) e "com a qualidade que expresse uma dimensão internacional" (PE2)

Percebe-se que os pesquisadores capitaneiam redes nacionais e internacionais a partir de seu prestígio pessoal: "Então, eu, por exemplo, estou pesquisando a questão do direito à educação das pessoas com deficiência. Tá bom, então, eu me articulo com um grupo da França, com um grupo da Inglaterra" (PE2).

Nos casos dos entrevistados, vemos que, internacionalmente, a circulação geográfica se focou mais nos EUA, América Latina e Europa - atuando no reforço e no reconhecimento das redes. Também ocorre a criação de novas parcerias ou a ampliação das já existentes no território brasileiro. Podemos observar na fala de um professor que, ao refletir sobre contatos através das disciplinas da Educação, das diferentes instituições e países em que se situam, avalia:

Quase que a gente pirou, mas enfim, eu acho que você tem positivamente, um diálogo mais amplo internacionalmente - porque era muito Estados Unidos. Nós ampliamos muito com a Alemanha, com gente se formando na Alemanha, Itália menos, mas Europa, Espanha, alguns. E eu acho que esta abertura de horizonte foi muito legal e com isto você dialoga. Você vai lá no interior, [...] você tem grupos muito bons que pesquisam. (PE1)

Em um segundo nível, verificamos que o pesquisador precisa ter acumulado um conhecimento ao longo de sua trajetória de vida. Tanto para os momentos formais - como concursos ou solicitações de bolsas de estudo para si ou para outrem - quanto para momentos informais e inesperados. Esse capital fica acumulado e pode ser mobilizado para facilitar a circulação pelo campo. Não se trata apenas de conhecimentos científicos, mas envolve capital social e cultural 
que dão sustentação a uma desenvoltura para aproveitar oportunidades contingentes.

Podemos constatar esse fenômeno no relato de uma pesquisadora, que pôde aproveitar uma oportunidade surgida durante uma conversa com uma professora: "Conversei com luma pesquisadora estrangeira de referêncial que me perguntou 'já pensou em fazer um doutorado?'" (PE4). Nessa situação, a pesquisadora já dominava uma lingua estrangeira antes da fase do doutorado, uma habilidade que não era comum a todos os profissionais da área nessa etapa da carreira. Além disso, encontrava-se já no exterior a partir de sua participação em um curso apoiada por uma bolsa de estudos.

A pesquisa mostra que as relações interpessoais são extremamente importantes nesse campo. Por vezes, é a dimensão da relação afetiva ou política, e não necessariamente a profissional/ intelectual, que aparece como disparadora de uma situação de parceria acadêmica ou produção de conhecimento. O pesquisador também consegue perceber a faceta pessoalizada do campo e opera com base nela: "Então, as relações são relações pessoais, que eu convido para dar um seminário no meu grupo de pesquisa, porque eu também produzo um texto para um livro que algum colega está organizando" (PE6). A interação entre capital social e capital científico mostra que ambos estão objetivamente ajudando a formular a rede, mesmo que suas articulações não estejam subjetivamente claras.

Um dos elementos intermediários muito significativos são as bolsas de estudo, que muitas vezes permitem a extensão de suas redes de contatos no exterior. A bolsa concretiza uma relação institucional e permite o deslocamento físico: "Então, nós éramos, sem dúvida nenhuma, um centro de formação. Vinha gente do Brasil inteiro com bolsa - porque começaram as bolsas do MEC para o mestrado. Acho que isso é importante" (PE4).

Observamos também que há relações articuladoras que são consolidadas e atualizadas através dos eventos científicos. Assim como ocorre com as publicações, a capacidade dos eventos de aglutinar pessoas depende das figuras dos professores: "são pessoas ou que foram nossos alunos, ou fizeram pós-doc conosco ou são pessoas muito próximas do grupo de Trabalho e Educação da Anped e que, eventualmente, vêm para os seminários de estudos" (PE3).

Outros intermediários são os orientandos, incentivados a montar trajetórias internacionais. Os orientadores, ao mesmo tempo em que ensinam a lógica do campo, fortalecem a sua própria rede de interlocução com as ações dos estudantes. Isso ocorre especialmente quando estes chegam a cargos de prestígio: "Eu tenho uma ex-aluna que está na Universidade [omitido] (...). Então, escreve solicitando artigos, me convidando para participar de algum trabalho lá" (PE3).

Às vezes, as redes de relações se expandem para abrigar algum agente que atua como intermediário na relação com espaços não acadêmicos. Em geral o agente está vinculado a alguma instituição importante e que pode trazer mais capital para os envolvidos. Essa expansão é exposta em falas como a seguinte: "Nesse meio tempo, a [nome da orientanda omitido] se formou, fez concurso para a Inome da instituição omitido], então, é um projeto que envolve trabalho, educação e saúde porque é uma escola de nivel médio e faz parte desse nosso grupo" (PE3).

\section{Apetência para a intervenção socioeducacional}

No Brasil, os pesquisadores em Educação estão engajados em variadas atividades simultâneas à de pesquisa. Devido à configuração do campo científico brasileiro, os pesquisadores são também professores universitários, ou seja, estão dedicados também à docência. Além disso, podem estar envolvidos na gestão acadêmica e na interlocução entre academia e sociedade civil. Destaca-se o envolvimento com o setor educacional, seja no envolvimento com os sistemas e as instituições de ensino, seja no subsídio à formulação de políticas públicas.

Um ponto que é compartilhado pela maioria dos pesquisadores entrevistados e que parece caracterizar disposições no subcampo científico da Educação é o compromisso com a perspectiva 
de emancipação social. Os pesquisadores desejam aumentar o acesso de indivíduos à escola - seja facilitando o acesso dos alunos através de infraestrutura ou otimizando processos gerenciais - a um nivel de ensino bem delimitado - variável conforme o pesquisador. Esse compromisso, de valor moral, se expressa em práticas de pesquisa e crenças que se circunscrevem em problemas de pesquisa diferenciados, mas orientados por uma ideia de intervenção social para construir um devir. Essa normatividade se expressa, por exemplo, na seguinte fala: "O nosso campo [o da Educação] é um campo que exige prática. Premente!" (PE1), remetendo à ideia de ação para transformação.

A apetência para a intervenção socioeducacional faz parte do subcampo na medida em que os atores de destaque podem mobilizá-la como uma forma de obter reconhecimento e prestígio dos demais atores. Essa disposição é de tipo especial uma vez que marca a doxa própria do campo científico da Educação, como um senso comum valorativo socialmente compartilhado no campo. O fato de a emancipação ser discutida no campo científico de forma aberta pelos agentes não significa necessariamente assumir que é algo racionalizável e racionalizado, mas permite argumentar que a relevância enquanto disposição encontra-se no fato de haver naturalização sobre a discussão em torno do compromisso com o ativismo socioeducacional. Ou seja, discute-se como praticá-lo, e não a pertinência de sua presença na arquitetura do subcampo e nas estratégias de seus atores.

Os pesquisadores entrevistados evidenciam competências para perceber o contexto político que o envolve e de formular pesquisas que respondam a ele de alguma maneira. E, para esse fim, acionam todos os tipos de capitais acumulados anteriormente, associados de forma não necessariamente consciente, mas manifestada em uma estratégia incorporada. Mudanças de objeto ocorrem pela alteração do contexto da vida do pesquisador, pelas modificações em sua rede de relações, e pelos novos problemas sociais e educacionais que se apresentam continuamente. Essas percepções, que parecem manifestações isoladas e individuais, apontam para aspectos comuns entre os entrevistados: "percebi que havia na área uma carência de quem estudasse a questão da legislação (...) porque isso tudo estava entremeado pela busca da redemocratização" (PE2).

O pesquisador, portanto, após todas essas experiências com redes e espaços, acaba por cotejar o seu próprio ambiente com outros ambientes, através das interações, e o percebe mais vivamente. Nesse momento, consegue se preparar mais para perceber demandas e valorizar o seu capital, atuando desde as atividades de pesquisa sobre novos temas que se colocam como desafiadores em novas conjunturas.

O pesquisador em Educação possui a particularidade de estar presente em vários campos simultaneamente, tanto acadêmicos quanto não acadêmicos. Um traço próprio do campo da Educação é a aptidão para lidar com diferentes epistemologias simultaneamente. Há outras formas de conexão que não passam pela comunidade epistemológica, mas se relacionam a aspectos metodológicos ou de imersão no campo de pesquisa. Os grupos ou redes de investigação também são formalizadas com pessoas de fora do campo científico, o que ilustra o processo de reconversão do capital. Como reforçado anteriormente, os contatos começam muitas vezes a partir de relações pessoais: "Fui para [outro país] para fazer esse curso, já que ninguém queria uma bolsa que apareceu no Departamento. E uma amiga que trabalhava lá disse: 'você não quer? Você gosta [do país de destino]. Preenchi e veio" (PE4).

O diálogo com esses diferentes espaços influencia o subcampo ao promover uma diferenciação no trabalho dos pesquisadores. Esse tipo de movimento se associa a inclinações para revisar suas epistemologias e aceitar contribuições de outras áreas.

Outro espaço ocupado é o burocrático, não propriamente acadêmico. É nessas interlocuções que percebemos que o capital social leva a uma posição de prestígio, gerando capital político que serve de base para diferentes tipos de atuação: "Então, aí eu tive um enorme desafio nessa di- 
reção porque quando (...) assumiu a reitoria, me convidou pra ser pró-reitora de graduação" (PE5). Essa foi uma oportunidade de gestão, mas outras oportunidades podem aparecer nas trajetórias dos pesquisadores. "Porque ai a ideia é que eles [professores da educação básica] que assumiriam esse trabalho de pesquisa com outras escolas e nós ficariamos numa assessoria a eles de uma outra forma" (PE5). Ou ainda: "Às vezes a gente faz das tripas coração. É para falar para professor? A gente vai, a gente vai para escolas, sindicato.... (...) Também com os movimentos sociais" (PE3).

\section{Discussão}

De modo articulado a disposições mais comuns no campo científico, encontramos no subcampo da Educação uma disposição mais especifica, que vincula capital cientifico, capital social e capital político. Os capitais social e político aqui referidos estabelecem conexões para além do campo científico. Essa combinação estrutura o campo por dentro ao exigir um habitus especifico de resposta para obter sucesso no campo. $O$ pesquisador de destaque em Educação, portanto, pode conjugar diferentes universos simbólicos: não apenas o típico acadêmico, mas também os dos sistemas de ensino, das escolas, dos sindicatos, dos movimentos sociais.

Essa articulação de capitais, ainda que dotada de alguma coerência prática, não é necessariamente consciente. De fato, lidamos com a hipótese de que é preciso que o pesquisador incorpore de forma tácita os esforços para estabelecer essas relações entre os diferentes campos. É com essa assimilação que se torna possivel produzir no volume exigido pelas politicas cientificas do tempo atual, conciliando essa performance com um ethos de intervenção socioeducacional. Nos depoimentos, essa disposição se ilustra na fala de um pesquisador que, ao ser confrontado com o conjunto de suas produções, não consegue recordar do motivo de um pesquisador aparecer nela: "Provavelmente deve ser pelos estudos daquele grupo (...). É possivel. Esse aqui, nem sei quem é" (PE2).

O conhecimento e as relações sedimentadas, por vezes, aparecem inconscientemente na ca- pacidade analítica: o pesquisador não lembra de onde o aprendeu. Portanto, a relação que se estabelece não é a de propriamente saber enumerar seus capitais científico e social para impô-los, mas sim de empregar competências para fazer resultar mais capital simbólico.

Dentre os pesquisadores entrevistados, detectamos uma disposição mais geral à colaboração: um estado do agente científico de chamar outros agentes científicos para si, estabelecendo vinculos em redes mais fortificadas. A disposição atua como uma tendência do agente cientifico a aceitar com mais frequência pedidos ou ideias de colaboração, delimitado por outros elementos, como disponibilidade de tempo, interesse científico, proximidade temática. Encarar cooperação como uma disposição que pode articular uma competência própria de operar ludus a uma apetência à intervenção socioeducacional significa destacá-la como uma estratégia de ação peculiar. Trata-se de certa atitude mental, isto é, forma de pensar, ver e agir que produz a prática da cooperação, dotando o subcampo científico da Educação de uma dinâmica própria.

As condições estruturais - requisitos do CNPq para ter uma bolsa, recursos para estabelecer contatos à distância com potenciais parceiros, luta por reconhecimento entre os pares - estimulam, em um sentido objetivo, e premiam a prática da cooperação dentro do campo e para além dele. Isso ocorre porque dela advém maior produtividade. A cooperação, enquanto disposição cientifica, reforça-se dentro do que pode ser definido como um habitus recorrente entre pesquisadores da área. No subcampo da Educação, ao lado do capital científico puro e do capital político próprio da academia, outros capitais sociais e políticos são importantes como fatores de inserção e repercussão dos trabalhos. Os pesquisadores se tornam mais atraentes tanto para atores que estão integrados ao meio acadêmico como àqueles que estão fora dele, e ocupam posições sociais e políticas relevantes em temas educacionais.

Como observado por Santos e Azevedo (2009), há nas exigências de atuação do pesquisador em 
Educação uma tendência distensora que pode mesmo ensejar uma contradição. Ele deve, ao mesmo tempo, distanciar-se suficientemente do mundo político para produzir conhecimento científico sobre ele e estabelecer contato com essa realidade, propondo pontos de intervenção. Essas duas frentes de atividades têm tempos distintos e quase opostos: uma demanda amadurecimento crítico e outra, a ação premente.

\section{Considerações finais}

Compreendemos que a atuação na pesquisa em Educação no Brasil apresenta um sistema de valores próprios, que se associam à lógica geral do campo científico, e são expressos nas disposições dos pesquisadores. Esses patrimônios de disposições, adquiridos no processo de formação e de participação na área de pesquisa em Educação, contribuem para a obtenção dos produtos com base nos quais se arbitram as disputas no campo. O fato de que esse sistema de valores é adjuvante, mas não central, caracteriza a área da pesquisa acadêmica em Educação como um subcampo e não como um campo autônomo.

Os pesquisadores em Educação analisados demonstram que estar envolvido com a instância educativa tem íntima relação com a atividade de pesquisa e têm consequências epistemológicas importantes. Há uma reflexividade não apenas técnico-científica, mas também ético-valorativa vinculadas ao "fazer Educação". Esse envolvimento exige respostas imediatas, cotidianas, e, portanto, informa a composição de um habitus próprio do subcampo, marcado pela incorporação de temporalidades conflitantes: a da pesquisa e a da ação, mediadas por complexas redes de interlocução. A possibilidade de que esse habitus multifacetado se apresente com distintas ênfases leva a uma variedade de tipos de conduta no subcampo que pode ser maior do que em outros segmentos do campo científico. Disso decorrem, maior dificuldade de obter coesão e homogeneidade, tornando também mais desafiador manter a autonomia do subcampo.

\section{Referências}

Bianchetti, L., Valle, I. R., \& Pereira, G. R. de M. (2015). O fim dos intelectuais acadêmicos? Induções da Capes, desafios às associações científicas e a emergência do intelectual institucionalizado. Autores Associados.

Bourdieu, P. (2012). O poder simbólico (16. ed.). Bertrand Brasil.

Bourdieu, P. (1983). Sociologia. Ática.

Bourdieu, P. (2004). Usos sociais da ciência. Unesp.

Comissão de Aperfeiçoamento de Pessoal de Nivel Superior. (2017). Relatório da Avaliação Quadrienal 2017. Ministério da Educação. https://www.gov.br/capes/ $\mathrm{pt}$-br/centrais-de-conteudo/documentos/avaliacao/ copy_of_quadrienal_2017_educacao.pdf

Caregnato, C. E., Leite, D., \& Sfredo Miorando, B. (2016). Pesquisadores e legitimidade científica no campo da Educação. Linhas criticas, 22(47), 189-209. https://doi. org/10.26512/lc.v22i 47.4813

Caregnato, C. E., Sfredo Miorando, B., \& Leite, D. (2018) O campo da educação no Brasil: mudanças em atributos para legitimação dos pesquisadores. Revista Brasileira de Politica e Administração da Educação, 34(1), 211-232. https://doi.org/10.21573/vol34n12018.73465

Conselho Nacional de Desenvolvimento Científico e Tecnológico. (2015). Critérios de julgamento CA-ED. Ministério da Ciência, Tecnologia e Inovações. http:// cnpq.br/web/guest/view/-/journal_content/56_INSTANCE_ooED/10157/5966303

Cunha, R. B., \& Prado, G. do V. T. (2007). A produção de conhecimento e saberes do/a professor/a-pesquisador/a. Educar, 30(1), 251-264. https://doi.org/10.1590/ $\underline{\text { S0104-40602007000200016 }}$

Lahire, B. (2002). O homem plural: os determinantes da ação. Vozes.

Lahire, B. (2004). Retratos sociológicos: disposições e variações individuais. Artmed.

Mancebo, D. (2013). Trabalho docente e produção de conhecimento. Psicologia \& Sociedade, 25(3), 519-526. https://doi.org/10.1590/S0102-71822013000300006

Portocarrero, V. (1994). Filosofia, história e sociologia das ciências l: abordagens contemporâneas. FIOCRUZ.

Santos, A. L. F. dos; \& Azevedo, J. M. L. de (2009). A pós-graduação no Brasil, a pesquisa em educação e os estudos sobre a política educacional: os contornos da constituição de um campo acadêmico. Revista Brasileira de Educação, 14(42), 534-550. https://doi.org/10.1590/ S1413-24782009000300010

Severino, A. J. (2009). Pós-graduação e pesquisa: o processo de produção e de sistematização do conhecimento. Revista Diálogo Educacional, g(26), 13-27. http://dx.doi.org/10.7213/rde.vgi26.3640 


\section{Célia Elizabete Caregnato}

Doutora em Educação pela Universidade Federal do Rio Grande do Sul (UFRGS), em Porto Alegre, RS, Brasil; professora associada na Faculdade de Educação da Universidade Federal do Rio Grande do Sul (UFRGS), em Porto Alegre, RS, Brasil.

\section{Bernardo Sfredo Miorando}

Doutor em Educação pela Universidade Federal do Rio Grande do Sul (UFRGS), em Porto Alegre, RS, Brasil; bolsista de desenvolvimento institucional da Universidade Federal de Ciências da Saúde de Porto Alegre (UFCSPA) e pós-doutorando na Pontificia Universidade Católica do Rio Grande do Sul (PUCRS), em Porto Alegre, RS, Brasil.

\section{Ricardo Cortez Lopes}

Doutor em Sociologia pela Universidade Federal do Rio Grande do Sul (UFRGS), em Porto Alegre, RS, Brasil; coordenador de Aprendizagem na Faculdade CMB e professor conteudista em cursos superiores de Ciências Sociais, em Porto Alegre, RS, Brasil.

\section{Vinicius Foletto Bevilaqua}

Doutor em Sociologia pela Universidade Federal do Rio Grande do Sul (UFRGS), em Porto Alegre, RS, Brasil; pesquisador no grupo de pesquisa Trabalho e Crítica Social (PPGS-UFRGS), em Porto Alegre, RS, Brasil.

\section{Endereço para correspondência}

Célia Elizabete Caregnato

Universidade Federal do Rio Grande do Sul

Av. Paulo Gama, 110, Prédio 12.201, sala 801

Farroupilha, 90046-900

Porto Alegre, RS, Brasil

Os textos deste artigo foram revisados pela Poá Comunicação e submetidos para validação do(s) autor(es) antes da publicação. 